DOI: $10.32481 / \mathrm{djph} .2021 .07 .016$

\title{
Educational Interventions to Promote COVID-19 Vaccination Among Parents
}

Julia Pascucci

University of Delaware; Intern, Delaware Academy of Medicine/Delaware Public Health Association

\section{Introduction}

The topic of COVID19 Vaccine Education for Caregivers (CVEC) was chosen for this internship project in an attempt to contribute to ending the global pandemic. The COVID19 pandemic has pushed the American public to take public health measures seriously in order to protect themselves and others. Pandemic-induced fears have also generated a significant amount of anxiety throughout many people in the country in regards to confusion and uncertainty regarding the COVID19 pandemic information as well as vaccine information. American adults caring for children are experiencing higher levels of stress, compared to adults without children, as they have to manage additional challenges regarding at-home care in the absence of traditional schooling and extracurricular activities. ${ }^{1}$

In addition to making vaccination decisions for themselves, these caregivers are also responsible for making healthcare decisions for their children, which is why it is extremely important that they have the information necessary to make informed decisions to receive COVID19 vaccination. CVEC was designed to educate and answer questions caregivers may have in order for them to feel educated and comfortable in receiving COVID19 vaccination. Working with the Delaware Academy of Medicine and the Delaware Public Health Association, CVEC resources were published online through the Immunization Coalition of Delaware, which works to ensure nobody in Delaware suffers from vaccine preventable illnesses.

\section{Background}

COVID-19 is a global pandemic that is quickly spreading around the world, infecting over 33 million Americans by May 2021 and has killing over 591,000 people in the United States. ${ }^{2}$ Social distancing measures were shown early on to be one of the most effective ways in limiting the spread of SARS-CoV-2, which led to the enforcement of practices such as wearing a mask, limiting gatherings, and keeping six feet apart. ${ }^{3}$ Global disease epidemiologists state that 70 to 80 percent of the population will need to get the COVID-19 vaccination in order to control the COVID-19 global pandemic. ${ }^{4}$

\section{Operation Warp Speed \& Emergency Use Authorization}

Operation Warp Speed (OWS) was implemented in the United States with the goal of developing, making, and distributing millions of safe and effective vaccine doses for COVID-19 in response to the global pandemic. This has led to the development of multiple effective vaccines beginning to be distributed to the public in early 2021. COVID-19 vaccine development has been in progress since January 2020, with phase one studies being started in March and phase three trials starting in May. By the end of 2020, OWS had announced six vaccines in their portfolio in partnership with the following companies: Moderna, Pfizer/BioNTech, AstraZeneca, Janssen, Novavax and Sanofi/GSK. ${ }^{5}$ The first BNT162b2 mRNA COVID-19 vaccine released by 
Pfizer had an efficacy of 95\%, and a second mRNA-1273 SARS-CoV-2 vaccine was released by Moderna with an efficacy of $94.1 \%{ }^{6,7}$

Vaccine development in public health emergencies are atypical, and funded by organizations like OWS so that money and funding is not a limit to companies developing multiple potential vaccines. The US Food and Drug Administration (FDA) released both Moderna's and Pfizer's/BioNTech's mRNA COVID-19 vaccines under an Emergency Use Authorization (EUA) in December 2020. Johnson and Johnson's single dose vaccine proving a $66.9 \%$ efficacy gained EUA approval in March $2021 .{ }^{8}$ EUAs are issued in order to facilitate vaccine availability before companies obtain official licensure because this process is known to take a long time. Efforts to quickly find an effective vaccine have not sacrificed the safety of the vaccine or the integrity and standards of the FDA approval process. ${ }^{9}$

\section{Misinformation and Fake News Influence Vaccine Hesitancy}

Despite the rigorous vaccine approval process, a distrust in the American government, the spread of misinformation and 'fake news' has led many Americans to be skeptical of the COVID-19 vaccines, which has major implications for public health. ${ }^{10}$ Social media attacks are one tool used in opposition to vaccination efforts, with a plethora of misinformation spread on popular sites such as Twitter or Facebook, which many Americans rely on for their news. Research supports that misinformation and conspiracy theory campaigns are motivated by the spread of distrust in the government rather than any goal relating to health or safety. These attacks are a serious threat to national security and are known to happen during moments of high political tension and at the start of national vaccination campaigns; creating a perfect storm for the COVID-19 pandemic during the 2020 US presidential election and the release of a new coronavirus vaccine. ${ }^{10}$

Social media platforms have made it easier for anti-vaccination misinformation to spread, even some misinformation shared by leaders and celebrities such as former US President Donald J.

Trump. ${ }^{11}$ Social media platforms are also designed to connect like-minded people, meaning that those sharing fake news will be directed to more sites to support their suspicions. ${ }^{12}$ Fake news on social media sites such as Twitter is $70 \%$ more likely to be retweeted than accurate and truthful news. ${ }^{13}$ The emergence and rapid spread of this new wave of vaccine and pandemic misinformation has prompted the World Health Organization (WHO) to publish a mythbusters site to combat popular conspiracies surrounding COVID-19 and the vaccine, such as 5G network virus transmission and hydroxychloroquine treatment. ${ }^{14}$

\section{Politicization of the COVID-19 Pandemic in the United States}

In this new wave of vaccine hesitancy surrounding the COVID-19 vaccine, association of health behaviors to end the global pandemic with personal identity and political affiliation has changed the way the American public perceives the pandemic. ${ }^{15}$ One of the most important messages for the American public to understand is that vaccination is not a liberal nor conservative ideology. Many people embraced public health initiatives such as mask wearing and social distancing, however people who oppose those public health measures are likely to oppose a vaccine as they may view these initiatives as a threat to their freedom and ultimately their democracy. ${ }^{16}$ Antiscience ideologies such as anti-mask or anti-vax ideologies use similar arguments tied to longstanding concerns surrounding public health initiatives such as compulsory vaccinations. ${ }^{17}$ 
The impact these associations will have on the United States' ability to recover from the pandemic are largely unknown, but it is important for people not to see political or personal identity as a barrier to getting vaccinated.

\section{COVID-19 Vaccine Hesitancy}

COVID-19 vaccine hesitancy has varied throughout the course of the pandemic, and the proportion of the US adult population willing to get vaccinated has fluctuated in 2020 from $72 \%$ in May down to $51 \%$ in September, back up to $60 \%$ in November; $18 \%$ of Americans who indicated they were not comfortable with getting the vaccine said they would be open to vaccination once other people started getting it and more information becomes available. ${ }^{18}$

In order to combat vaccine hesitancy, vaccination efforts 'may need to go beyond just communications campaigns correcting misinformation about a COVID-19 vaccine to also focus on re-establishing public trust in government agencies"19. A survey asked participants, "When a vaccine for the coronavirus becomes available, will you get vaccinated?" with response options of yes, no, or not sure. Of the participants that answered 'not sure' or 'no,' almost half of the responses related to anti-vaccination beliefs as well as lack of trust in the vaccine, vaccine developmental process, the government, and the CDC. Common concerns about the vaccine to those who answered 'not sure' were specific to the development of the coronavirus vaccine, uncertainty regarding side effects and efficacy, and concern over the 'newness' of the vaccine; others needed additional information regarding the vaccine. ${ }^{20}$

\section{Vaccine Hesitancy Addressed Through Educational Interventions}

Vaccine hesitancy was common surrounding the Human Papillomavirus (HPV) vaccine for young girls and boys, leading to the development of HPV educational intervention sessions. ${ }^{21}$ This research also supported that access to accurate information is necessary for making informed health decisions regarding vaccinations, and showed how providing accurate information is a common component of behavioral interventions. ${ }^{22}$ These techniques, in conjunction with more recent studies evaluating the American perception of COVID-19 vaccines, can be applied to a vaccination education intervention for the COVID-19 vaccine.

\section{COVID-19 Vaccination Education for Caregivers (CVEC) to Combat Vaccine Hesitancy}

Adequate knowledge and disproving misinformation about the COVID-19 vaccine will drive informed health decisions for parents who make vaccine decisions for their minor children.American's attitudes towards receiving the vaccine are divided, with some waiting in line to get the vaccine while others actively protest against its development. This is why 'any successful marketing strategy will be multifaceted,' using a combination of key strategies found through consumer research and behavioral economics to promote vaccination. ${ }^{16}$ COVID-19 Vaccination Education for Caregivers (CVEC) will educate caregivers of middle- and highschool-aged children on the benefits of vaccination, as well as address questions and concerns from participants. In addition to actual knowledge about COVID-19 and the vaccine, it is important parents feel high levels of self-rated knowledge in order to feel confident in discussing the vaccine with their peers, as well as their own children. Given the influx of misinformation and uncertainty surrounding emerging COVID-19 vaccines, educational interventions designed 
to accurately inform parents about the COVID-19 vaccine are an important step in getting a majority of the population vaccinated in order to control the COVID-19 pandemic.

Vaccines have been able to make many dangerous childhood diseases rare, as now it is common for infants to receive dozens of vaccines in the first years of their life. ${ }^{22}$ Research on vaccine hesitancy and interventions aimed to combat vaccine hesitancy have commonly focused on parents, "who are the key propagators of vaccine hesitancy and consumers of anti-vaccine influences, while the children are the key victims. ${ }^{23}$ It is critical for adults - and specifically parents - to have accurate information regarding the COVID-19 vaccine.

\section{Theory of Planned Behavior}

In the late 1980s and early 1990s, the theory of planned behavior (TPB) was created as a revision to the theory of reasoned action (TRA). The aim of both theories is to predict and understand an individual's intention to engage in a behavior at a specific time or place. An issue soon recognized in the TRA was that it operated under the assumption of total volitional control, and could not be applied to behaviors in which at least in part determined by factors outside an individual's volitional control. ${ }^{24}$ An elaboration was made to turn the TRA to the TPB, in order to address human behaviors and actions that would require knowledge, skills, resources, or triumph over environmental obstacles. ${ }^{25}$ In the TPB a construct was introduced to address the non-volitional part of human behavior. This construct is 'perceived behavioral control' and is defined as the perceived difficulty of engaging in a behavior.

The TPB was designed to predict an individual's intention to engage in a behavior at a specific time or place. ${ }^{25}$ The key components to the TPB are behavioral intentions, which are influenced by the attitude about the likelihood that the behavior will have the expected outcome, and the subjective evaluation of the risks and benefits associated with that outcome. ${ }^{26}$ The TPB imposes the use of constructs collectively representing an individual's ability to make a decision, which fall into three types of beliefs: behavioral, normative, and control. The TPB has "been used successfully to predict and explain a wide range of health behaviors and intentions including smoking, drinking, health services utilization, breastfeeding, and substance use." ${ }^{26}$ In order to use the TPB, it is necessary to identify the constructs and beliefs the theory is based upon; including behavioral beliefs, normative beliefs, and control beliefs.

\section{TPB Constructs}

Hales, et al. defined and measured the TPB constructs to evaluate health behaviors regarding postpartum physical activity. ${ }^{27}$ The definitions used in that study were used to define the same constructs in this study. The seven constructs of the TPB include:

- Behavioral beliefs

- Normative beliefs

- Control beliefs

- Subjective norms

- Perceived behavior

- Attitude

- Intention 
Behavioral beliefs are perceived advantages and disadvantages of performing a behavior. Normative beliefs are the sense of approval or disapproval from family, friends, and physicians. Control beliefs are the resources allowing and the impediments stopping a person from engaging in a behavior. Attitude is an overall or general feeling regarding a behavior. A subjective norm is the perceived social pressure to perform a behavior. Perceived behavioral control is the perceived difficulty of engaging in a behavior. Intention is the plan or goal for performing the behavior in a given time period.

These constructs will be measured through a series of targeted survey questions presented at the beginning and end of the intervention to predict a participant's intention to get the COVID-19 vaccination. Similar to the HPV vaccination intervention, participants will answer survey statements designed to measure identified constructs stated above using a Likert scale in their responses on a 5 point scale (-2 to 2 ), anchored at each end by a descriptor ("strongly disagree" and "strongly agree"). ${ }^{27}$

\section{Theory of Planned Behavior in COVID-19 Vaccination Education}

For for the purpose of this intervention design, the behavior being studied is the decision to get the COVID-19 vaccine. Education on the COVID-19 vaccine and benefits of vaccination will be disseminated within this program to increase participant knowledge of the advantages of receiving a COVID-19 vaccine.

In the past, TPB constructs have been measured through a series of aimed survey questions (figure 1). ${ }^{27} \mathrm{CVEC}$ will include questions that will measure these identified constructs and will be delivered before and after the educational intervention session to participants. Measuring the constructs through the same series of survey questions before and after the intervention is delivered will determine if participants have changed their beliefs due to the intervention. The constructs will be measured by having participants answer statements relating to each construct (see Table 1).

Figure 1. TPB Constructs 


\section{Table 1}

Summary of the scales used in this study to quantify hypothesized constructs from the theory of planned behavior.

\begin{tabular}{|c|c|c|c|}
\hline Scale & Definition of what scale is measuring & $\begin{array}{l}\text { \# of } \\
\text { items }\end{array}$ & Hypothesized factor structure \\
\hline $\begin{array}{l}\text { Behavioral } \\
\text { Beliefs }\end{array}$ & $\begin{array}{c}\text { Perceived advantages and disadvantages of } \\
\text { performing a behavior }\end{array}$ & 6 & single latent factor indicated by 6 items \\
\hline $\begin{array}{l}\text { Normative } \\
\text { Beliefs }\end{array}$ & $\begin{array}{c}\text { Approval of behavior by spouse, family, } \\
\text { friends, and physician }\end{array}$ & 4 & single latent factor indicated by 4 items \\
\hline $\begin{array}{l}\text { Control } \\
\text { Beliefs }\end{array}$ & $\begin{array}{l}\text { Impediments and opportunities/resources } \\
\text { available for performing the behavior }\end{array}$ & 9 & single latent factor indicated by 9 items \\
\hline Attitude & $\begin{array}{l}\text { Overall feeling toward performing a given } \\
\text { behavior }\end{array}$ & 7 & single latent factor indicated by 7 items \\
\hline $\begin{array}{l}\text { Subjective } \\
\text { Norm }\end{array}$ & $\begin{array}{l}\text { Perceived social pressure to perform a } \\
\text { behavior }\end{array}$ & 1 & $\begin{array}{l}\text { single item indicator with error variance } \\
\text { fixed based on previous research }\end{array}$ \\
\hline $\begin{array}{c}\text { Perceived } \\
\text { Behavioral } \\
\text { Control }\end{array}$ & $\begin{array}{l}\text { Perceived difficulty of performing a } \\
\text { behavior }\end{array}$ & 3 & single latent factor indicated by 3 items \\
\hline Intention & $\begin{array}{l}\text { Plan or goal for performing a behavior in a } \\
\text { given time period }\end{array}$ & 1 & $\begin{array}{l}\text { single item indicator with error variance } \\
\text { fixed based on previous research }\end{array}$ \\
\hline
\end{tabular}

Table 1. TPB Constructs in CVEC Survey

\begin{tabular}{|l|l|}
\hline Construct & Statement Designed to Measure Construct \\
\hline Behavioral Belief & $\begin{array}{l}\text { If I were to receive the COVID-19 vaccine, I would be taking an } \\
\text { important step in ending the COVID-19 pandemic. }\end{array}$ \\
\hline Normative Belief & $\begin{array}{l}\text { My family and friends would approve of me getting the COVID-19 } \\
\text { vaccine. }\end{array}$ \\
\hline Control Belief & I am aware of vaccination resources in my area. \\
\hline Subjective Norms & My family and friends would want me to get the COVID-19 vaccine. \\
\hline $\begin{array}{l}\text { Perceived Behavioral } \\
\text { Control }\end{array}$ & $\begin{array}{l}\text { When I am eligible to receive the COVID-19 vaccine, it would be } \\
\text { easy for me to get one. }\end{array}$ \\
\hline Attitude & $\begin{array}{l}\text { The development of the COVID-19 vaccine has benefited the United } \\
\text { States. }\end{array}$ \\
\hline Intention & I intend to get the COVID-19 vaccine as soon as I am eligible. \\
\hline
\end{tabular}


DOI: $10.32481 / \mathrm{djph} .2021 .07 .016$

\section{Caregiver Vaccine Education for COVID-19}

The Kellogg Logic Model is an effective planning tool used in designing a well-planned program or action, and was used to implement this intervention (see Appendix A). CVEC was designed with the purpose of creating a short program aimed to educate parents with up to date information about the coronavirus vaccine. There are multiple reasons for implementing this intervention, but in a successful national recovery from a global pandemic it is important for parents to be knowledgeable about the coronavirus vaccine. This will characterize their behaviors regarding the vaccine, and help them make informed health decisions for themselves and their children. ${ }^{28}$ CVEC seeks to decrease COVID-19 vaccine hesitancy among parents of middle- and high-school-aged children in the State of Delaware.

Inputs are the constructs of the CVEC Logic Model representing the resources to be invested in order to conduct this intervention. One resource necessary is staff members, with one of them being a licensed medical professional in order to deliver the medical information to parents. Staff responsibilities will also include working with local middle and high schools to recruit parent participants, as well as designing virtual advertisements for sign ups. CVEC sessions will require a staff member to be a presenter, as well as another staff member to facilitate the Zoom to address any live chat questions from participants. This non-presenting staff member will also filter any questions regarding COVID-19 vaccines as well as information in the presentation to the medical professional presenter to be answered at the end of the session. Another resource necessary for this intervention is for all staff members to have access to a laptop and appropriate technology to run the Zoom program during sessions.

Outputs are the constructs of the CVEC Logic Model representing what the intervention plans to do (activities), and who it intends to reach (participation). CVEC was designed for parents with middle- and high-school-aged children in the State of Delaware. To find and identify participants the program will recruit parents from local middle and high schools throughout the State.

\section{CVEC Program Design}

The intervention will be delivered online via Zoom platform for a 40 minute period, with 5 minutes during the end used for participants to fill out their post-survey. Participants will be directed to submit questions into a chat box. The non-presenting staff member can address any participant questions or comments during the session, and there will be ten minutes at the end of the CVEC session for the medical presenter to answer questions asked by participants. The pre-intervention and post-intervention surveys will be delivered through SurveyMonkey. Links to the SurveyMonkey for the pre-surveys will be sent upon registering for a CVEC session. Links to the SurveyMonkey for the post-surveys will be sent out via the Zoom chat during the presentation. Participants will be using their email in submitting their survey for the purpose of linking their pre- and post- surveys. Upon completion of the pre- and post-survey, and after participating in the educational session, participants will be eligible to receive a gift card. Participants will not be able to see other participants and will only be able to hear and see the meeting hosts. Because participants cannot interact with one another, the number and location of those participating in each session will not impact individual participant experience. The program will recruit parents from at least two to three middle and/or high schools locally in the State of Delaware. 
CVEC will have 200 parents participate throughout the eight sessions offered, having an average attendance at every session of 25 participants. At the end of the educational session, participants will be entered into a drawing for a virtual $\$ 10$ Walgreens gift card.

All of the live educational sessions will be recorded, and at the end of all the sessions offered one presentation will be edited (including the live Q\&A section) and be emailed out to local middle and high schools that partnered with this program. Short term outcomes from these educational sessions will include participants' increased self-rated and objective knowledge about the COVID-19 vaccine, increased knowledge on how the COVID-19 vaccine was developed, and more complete knowledge of general information regarding COVID-19. Short term outcomes also include a shift in attitude and opinion to have parents be more accepting of the COVID-19 vaccination. Midterm outcomes include the action of parents deciding to get vaccinated once the option is available to them, and parents deciding to vaccinate their children from COVID-19 once a vaccine for children becomes available. Ultimately, long-term outcomes and impact of this intervention will be a decrease of general vaccine hesitancy among parents in Delaware.

\section{Discussion}

\section{Social Determinants of Health Addressed in CVEC}

Social determinants of health $(\mathrm{SDOH})$ have a large impact on the wellbeing and the quality of life, and are important in establishing health equity. There are many examples of SDOH that relate to caregivers in Delaware regarding COVID19 vaccination including education, discrimination, misinformed beliefs, and access to vaccination sites.

One of the main goals of the CVEC program is to address COVID-19 vaccine hesitancy and educate caregivers about COVID-19 vaccination in relation to themselves and their children (Appendix A). Education has proven to be a successful tool in addressing vaccine hesitancy, as seen in HPV vaccination intervention research studies conducted after the release of the cancerpreventing HPV vaccine in 2006. Past studies have proven that allowing parents to be knowledgeable about diseases and vaccine information will characterize their behaviors regarding vaccination, helping them make informed health decisions for themselves and the children they are responsible to make health decisions for.

Another aspect of the SDOH addressed in the CVEC program was to ensure participants that no vaccination discrimination is taking place against those of any ethnic background or financial class. COVID19 vaccination is available free of charge to all vaccine-eligible Delaweareans, regardless of whether a patient is insured or not. All participants were also informed that safety trials were conducted among participants of multiple backgrounds and ethnicities with no increased risk found. Participants were also informed their ethnic background would have no impact on which vaccine was available to them, as vaccine distribution and availability varies based largely on testing site capabilities and characteristics.

Vaccine hesitancy relating to the COVID19 pandemic has largely been fueled by the spread of misinformation, conspiracies and 'fake news' spread on television as well as on popular social media sites such as Twitter. These conspiracies are often believed by those who have lower levels of education, as lower levels of education are shown to have a positive correlation to those who are less likely to be skeptical of a simple solution to a complex problem. ${ }^{29} \mathrm{Common}$ misconceptions and popular conspiracy theories were disproved during the CVEC program and 
survey questions designed were aimed to examine the effectiveness of debunking of COVID-19 vaccine conspiracies through educational interventions. Furthermore, the research and biostatistics gathered from this study can be used to inform further research, specifically research regarding educational interventions regarding vaccine hesitancy.

The CVEC program addressed these SDOH discussed above and gave access to resources to assist those who wanted more information about the COVID-19 pandemic or vaccine. Resources were available for any participant with additional questions regarding COVID-19 vaccination or the pandemic as they were directed to contact the Delaware Public Health Call Center.

Additionally, at the end of the program a Frequently Asked Questions section was utilized to answer recurring questions and correct any common misconceptions held among participants.

\section{Initial Survey to Inform CVEC Design}

In February, an email announcement was sent out to parents of students attending selected middle- and high-schools to submit any questions they have regarding COVID-19 and COVID19 vaccines. The purpose of this survey was to allow parents to express what topics they feel are most important to address in learning about the COVID-19 vaccine, as well as drafting answers to a Frequently Asked Questions section to be delivered at the end of the educational session. At the end of the survey, participants entered their email address to be entered to win a $\$ 25$ Walgreens gift card. Participants had the option to identify whether they would like to be contacted about being part of a focus group for upcoming CVEC sessions and/or indicate if they would like to receive emails about upcoming CVEC program dates and times available to them.

\section{COVID-19 Vaccination Education for Caregivers}

At the end of February, a series of email announcements were sent out that informed parents of optional educational sessions on the COVID-19 vaccine beginning in March 2021. A focus group would meet on February 25th at 5pm to completely go through a sample CVEC session and use the feedback to develop the final presentation. Participants of the focus group would receive \$20 Walgreens gift cards at the end of the meeting through the emails they used to complete their pre- and post-surveys. The first announcement was sent out with a resource allowing parents to sign up for available online CVEC session time slots offered through Zoom. The educational sessions were offered during the two week time period of March 21 - March 28, 2021. Sign up slots were available for 6:30 pm on Monday and Wednesday nights, as well as $1: 00 \mathrm{pm}$ and $6: 30 \mathrm{pm}$ slots on Sundays.

\section{Implementation of CVEC}

At the beginning of the study, the research team reached out to 14 middle schools and 20 high schools in Delaware as prospective partners in the CVEC program (Appendix B). Out of the 34 combined prospective schools, responses were received from two schools.

\section{Modifications to Program Design}

Administrative obstacles stood in the way of distributing pre-surveys to prospective parents. Due to administrative rules, parent information could not be collected through survey responses for privacy reasons. Due to the lack of interest in participation as well as obstacles encountered in distributing the pre-survey, the surveys were not implemented. 
The CVEC program was also re-designed to be non-exclusive to schools, so any caregiver could sign up for a session. Flyers were distributed to caregivers at prospective schools, but no caregiver participants signed up (figure 2).

Figure 2. CVEC Flyer

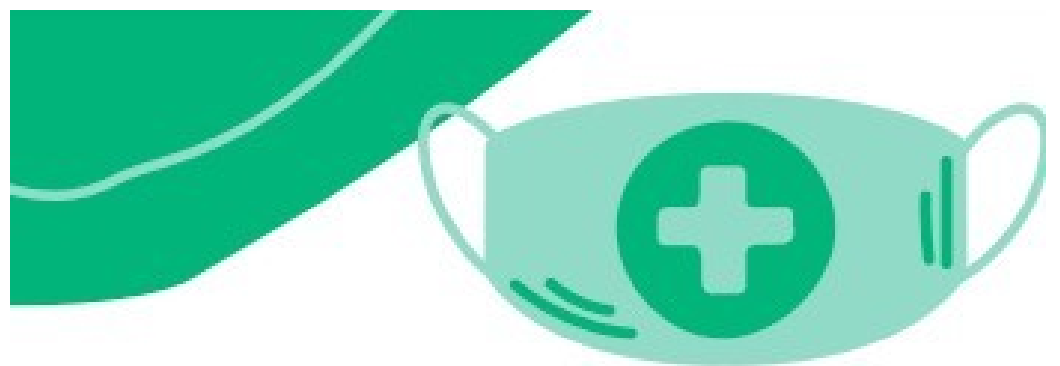

\section{April 21st @6:30pm}

\section{COVID19 Vaccine}

\section{Education for}

\section{Caregivers}

\section{in Delaware}

\section{Register Today! $\Rightarrow$ \\ Scan QR Code \\ OR Click to Register Online HERE}

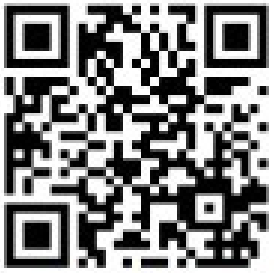

*(1) Participant will be drawn to recej/e a $10 \$$ Walgreens gift card at the end of the session

Due to these issues, the CVEC program was adapted to become an administered recording. CVEC education was made available to caregivers at any prospective schools with whom resources were shared. This video was uploaded to the website. ${ }^{30}$

Despite the limitations and obstacles encountered, the research team was still able to implement some of the initial program goals. The CVEC program was designed to address vaccine hesitancy among caregivers in order for them to make informed health decisions regarding COVID19 vaccination. Without the implementation of survey measures, it is impossible to interpret trends between pre- and post- survey results. This recorded program was shared with 
the original 34 middle and high schools. Printed brochures meant to be distributed to partner schools were replaced by sharing a link to the website of the CVEC page with the attached recording of the program. These modifications were made in hopes to make the CVEC program more accessible to caregivers who might benefit from participation, as well as helping to overcome obstacles with privacy issues and survey distribution.

\section{Conclusion}

During my internship at The Delaware Academy of Medicine/Delaware Public Health Association (Academy/DPHA), I had the pleasure of creating my own independent research project. I chose to do research involving COVID-19 vaccination in the hopes of making a difference in my local community during the global pandemic. Reviewing past research studies regarding HPV vaccination education, I felt inspired by seeing how educational interventions given to caregivers have shown to decrease vaccine hesitancy. Furthermore, it has been proven that caregivers have an increase in objective knowledge about vaccination post intervention completion, they feel more comfortable spreading that information with those in their community. The COVID-19 Vaccination Education for Caregivers program I created falls in line with the Academy/DPHA mission to enhance the wellbeing of the community through education and the promotion of public health.

During my internship at the Academy/DPHA and the creation of CVEC, I was able to gain valuable skills in time management and professionalism as well as having the experience to learn more about research and the process of research design.

\section{References}

1. Adams, E. L., Smith, D., Caccavale, L. J., \& Bean, M. K. (2021, April 8). Parents are stressed! Patterns of parent stress across COVID-19. Frontiers in Psychiatry, 12, 626456. https://doi.org/10.3389/fpsyt.2021.626456 PubMed

2. Centers for Disease Control and Prevention. (2021). COVID Data Tracker. Retrieved from https://covid.cdc.gov/covid-data-tracker/

3. McGrail, D. J., Dai, J., McAndrews, K. M., \& Kalluri, R. (2020, July 30). Enacting national social distancing policies corresponds with dramatic reduction in COVID19 infection rates. PLoS One, 15(7), e0236619. https://doi.org/10.1371/journal.pone.0236619 PubMed

4. Elbeshbishi, S., \& King, L. (2020). Exclusive: Two-thirds of Americans say they won't get COVID-19 vaccine when it's first available, USA TODAY/Suffolk Poll shows. Retrieved from https://www.usatoday.com/story/news/politics/2020/09/04/covid-19-two-thirds-uswont-take-vaccine-right-away-poll-shows/5696982002/

5. Slaoui, M., \& Hepburn, M. (2020). Developing Safe and Effective Covid Vaccines Operation Warp Speed's Strategy and Approach. Retrieved from https://www.nejm.org/doi/full/10.1056/NEJMp2027405

6. Baden, L. R., El Sahly, H. M., Essink, B., Kotloff, K., Frey, S., Novak, R., . . Zaks, T., \& the COVE Study Group. (2021, February 4). Efficacy and safety of the mRNA-1273 SARSCoV-2 vaccine. The New England Journal of Medicine, 384(5), 403-416. https://doi.org/10.1056/NEJMoa2035389 PubMed 
7. Polack, F. P., Thomas, S. J., Kitchin, N., Absalon, J., Gurtman, A., Lockhart, S., . . Gruber, W. C., \& the C4591001 Clinical Trial Group. (2020, December 31). Safety and efficacy of the BNT162b2 mRNA COVID-19 Vaccine. The New England Journal of Medicine, 383(27), 2603-2615. https://doi.org/10.1056/NEJMoa2034577 PubMed

8. Sadoff, J., Gray, G., Vandebosch, A., Cárdenas, V., Shukarev, G., Grinsztejn, B., . . . Douoguih, M., \& the ENSEMBLE Study Group. (2021, June 10). Safety and efficacy of single-dose Ad26.COV2.S vaccine against COVID-19. The New England Journal of Medicine, 384(23), 2187-2201. https://doi.org/10.1056/NEJMoa2101544 PubMed

9. US Food \& Drug Administration. (2020). Emergency use authorization for vaccines explained. Retrieved from https://www.fda.gov/vaccines-bloodbiologics/vaccines/emergency-use-authorization-vaccines-explained

10. Bliss, K. E., \& Morrison, J. S. (2021). The risks of misinformation and vaccine hesitancy within the COVID-19 crisis. Retrieved from https://www.csis.org/analysis/risksmisinformation-and-vaccine-hesitancy-within-covid-19-crisis

11. Benecke, O. \& DeYoung, S.E. (2019). Anti-vaccine decision-making and measles resurgence in the United States. Global pediatric health, 6, 2333794X19862949. https://doi.org/10.1177/2333794X19862949

12. Menczer, F., \& Hills, T. (2020). Information overload helps fake news spread, and social media knows it. Retrieved from https://www.scientificamerican.com/article/informationoverload-helps-fake-news-spread-a nd-social-media-knows-it/

13. Vosoughi, S., Roy, D., \& Aral, S. (2018, March 9). The spread of true and false news online. Science, 359(6380), 1146-1151. https://doi.org/10.1126/science.aap9559 PubMed

14. World Health Organization. (2020). COVID-19 mythbusters. Retrieved from https://www.who.int/emergencies/diseases/novel-coronavirus-2019/advice-for-public/mythbusters

15. Pedersen, M. J., \& Favero, N. (2020, May 22). Social distancing during the COVID-19 pandemic: Who are the present and future noncompliers? Public Administration Review, 80(5), 805-814. https://doi.org/10.1111/puar.13240 PubMed

16. Wood, S. \& Schulman, K. (2021). Beyond politics - promoting COVID-19 vaccination in the United States. NEJM.org. Retrieved from https://doi.org/10.1056/NEJMms2033790

17. Brig, K. (2020). Anti-vax to anti-mask: Processing anti-science claims during a pandemic [Web blog post]. Retrieved from https://biomedicalodyssey.blogs.hopkinsmedicine.org/2020/09/anti-vax-to-anti-maskprocessing-anti-science-claims-during-a-pandemic/

18. Funk, C., \& Tyson, A. (2020). Intent to get a COVID-19 vaccine rises to $60 \%$ as confidence in research and development process increases. Retrieved from https://www.pewresearch.org/science/2020/12/03/intent-to-get-a-covid-19-vaccine-rises-to60 -as-confidence-in-research-and-development-process-increases/

19. Guidry, J. P. D., Laestadius, L. I., Vraga, E. K., Miller, C. A., Perrin, P. B., Burton, C. W., . . Carlyle, K. E. (2021, February). Willingness to get the COVID-19 vaccine with and 
DOI: $10.32481 / \mathrm{djph} .2021 .07 .016$

without emergency use authorization. American Journal of Infection Control, 49(2), 137142. https://doi.org/10.1016/j.ajic.2020.11.018 PubMed

20. Fisher, K. A., Bloomstone, S. J., Walder, J., Crawford, S., Fouayzi, H., \& Mazor, K. M. (2020, December 15). Attitudes toward a potential SARS-CoV-2 vaccine: A survey of U.S. adults. Annals of Internal Medicine, 173(12), 964-973. https://doi.org/10.7326/M20-3569 $\underline{\text { PubMed }}$

21. Reiter, P. L., Stubbs, B., Panozzo, C. A., Whitesell, D., \& Brewer, N. T. (2011, November). HPV and HPV vaccine education intervention: Effects on parents, healthcare staff, and school staff. Cancer Epidemiol Biomarkers Prev, 20(11), 2354-2361. https://doi.org/10.1158/1055-9965.EPI-11-0562 PubMed

22. Stanford Children's Health. (2021). Why childhood immunizations are important. Retrieved from https://www.stanfordchildrens.org/en/topic/default?id=why-childhood-immunizationsare-important-1-4510

23. Damnjanović, K., Graeber, J., Ilić, S., Lam, W. Y., Lep, Ž., Morales, S., . . Vingerhoets, L. (2018, June 13). Parental decision-making on childhood vaccination. Frontiers in Psychology, 9, 735. https://doi.org/10.3389/fpsyg.2018.00735 PubMed

24. Sheppard, B., Hartwick, J., \& Warshaw, P. (1988). The theory of reasoned action: A metaanalysis of past research with recommendations for modifications and future research. The Journal of Consumer Research, 15(3), 325-343. Retrieved from http://www.jstor.org/stable/2489467 https://doi.org/10.1086/209170

25. Ajzen, I. (1991). The theory of planned behavior. Organizational Behavior and Human Decision Processes, 50, 179-211. https://doi.org/10.1016/0749-5978(91)90020-T

26. LaMorte, W. W. (2019, September 9). Behavioral change models: The theory of planned behavior. Retrieved from https://sphweb.bumc.bu.edu/otlt/mphmodules/sb/behavioralchangetheories/BehavioralChangeTheories3.html

27. Hales, D., Evenson, K. R., Wen, F., \& Wilcox, S. (2010, July-August). Postpartum physical activity: Measuring theory of planned behavior constructs. American Journal of Health Behavior, 34(4), 387-401. https://doi.org/10.5993/AJHB.34.4.1 PubMed

28. Abraham, C., \& Michie, S. (2008, May). A taxonomy of behavior change techniques used in interventions. Health Psychol, 27(3), 379-387. PubMed https://doi.org/10.1037/0278$\underline{6133.27 .3 .379}$

29. van Prooijen, J. W. (2017, January-February). Why education predicts decreased belief in conspiracy theories: Education and conspiracy beliefs. Applied Cognitive Psychology, 31(1), 50-58. https://doi.org/10.1002/acp.3301 PubMed

30. Immunization Coalition of Delaware. (2021). COVID-19 Vaccination Education for Caregivers. Retrieved from http://www.immunizedelaware.org/covid19-vaccinationeducation-for-caregivers 
Appendix A: CVEC Logic Model

\begin{tabular}{|c|c|c|c|c|c|}
\hline Goal & & $\begin{array}{l}\text { Implementation } \\
\text { Activities/Objectives }\end{array}$ & Short Term Deliverables & Mid Term Outputs & Long Term Outcomes \\
\hline \multirow[t]{4}{*}{ Engagement } & 1 & $\begin{array}{l}\text { Identify middle and high } \\
\text { schools locally in the state } \\
\text { of DE to offer optional } \\
\text { CVEC sessions held } \\
\text { virtually }\end{array}$ & $\begin{array}{l}\text { 2-3 Partnered schools } \\
\text { identified and letter of } \\
\text { potential participation sent } \\
\text { by } 2 / 22\end{array}$ & $\begin{array}{l}\text { Partner schools } \\
\text { participating in CVEC } \\
\text { sessions send out initial } \\
\text { survey via email to allow } \\
\text { parents to ask any } \\
\text { COVID-19 vaccine related } \\
\text { questions \& identify } \\
\text { future FG participants }\end{array}$ & $\begin{array}{l}\text { Additional schools } \\
\text { identified as needed }\end{array}$ \\
\hline & 2 & $\begin{array}{l}\text { Survey to identify reasons } \\
\text { for COVID-19 vaccine } \\
\text { hesitancy among parents } \\
\text { of middle and high school } \\
\text { aged children }\end{array}$ & $\begin{array}{l}\text { Optional survey for } \\
\text { parents to submit any } \\
\text { questions regarding } \\
\text { COVID- } 19 \& \text { the vaccine } \\
\text { sent out to all partnered } \\
\text { schools on } 2 / 25\end{array}$ & $\begin{array}{l}\text { Focus group participate in } \\
\text { CVEC curriculum shaped } \\
\text { by initial survey questions } \\
\text { by } 3 / 11\end{array}$ & \\
\hline & 3 & $\begin{array}{l}\text { FG to identify which } \\
\text { topics caregivers feel most } \\
\text { uncertain about regarding } \\
\text { COVID-19 pandemic \& } \\
\text { COVID-19 vaccine } \\
\text { questions for themselves } \\
\text { and their children }\end{array}$ & $\begin{array}{l}\text { Final CVEC curriculum \& } \\
\text { FAQ section created } \\
\text { based on focus group by } \\
3 / 18\end{array}$ & & \\
\hline & 4 & $\begin{array}{l}\text { Survey of behavioral } \\
\text { measures }\end{array}$ & $\begin{array}{l}\text { Email registration } \& \text { pre- } \\
\text { survey for available } \\
\text { CVEC sessions sent by } \\
3 / 14\end{array}$ & $\begin{array}{l}\text { Pre-survey measures in } \\
\text { comparison to post-survey } \\
\text { measures to identify } \\
\text { behavioral change }\end{array}$ & $\begin{array}{l}\text { Use demographic } \\
\text { answers to guide the } \\
\text { development of future } \\
\text { research }\end{array}$ \\
\hline Education & 1 & $\begin{array}{l}\text { CVEC sessions will be } \\
\text { conducted to address } \\
\text { COVID-19 vaccine }\end{array}$ & $\begin{array}{l}\text { Eight CVEC sessions are } \\
\text { offered via Zoom at } \\
\text { 6:30pm EST }\end{array}$ & $\begin{array}{l}\text { Increased. objective } \\
\text { knowledge about } \\
\text { COVID19 vaccine \& }\end{array}$ & $\begin{array}{l}\text { COVID19 vaccine } \\
\text { hesitancy is decreased } \\
\text { among parent }\end{array}$ \\
\hline
\end{tabular}




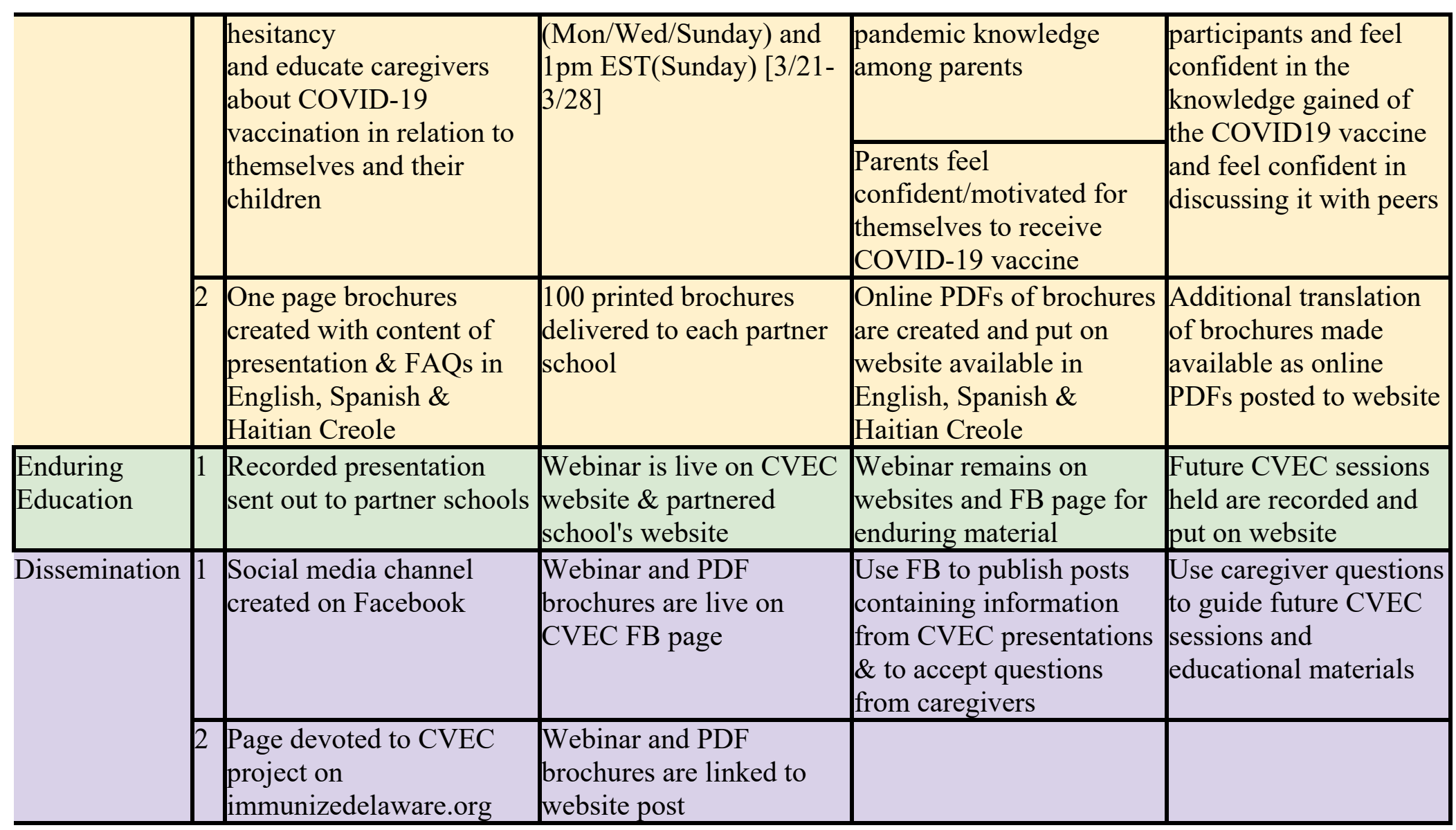


DOI: 10.32481/djph.2021.07.016

\section{Appendix B: List of Prospective Delaware Schools}

Middle Schools (14)

- Newark Charter School*

- Shue-Medill Middle School

- Gauger-Cobbs Middle School

- The Brennen School

- George V Kirk Middle School (Ogletown Middle School)

- Skyline Middle School

- A.I. duPont Middle School

- DuPont (HB) Middle School

- Stanton Middle School

- George Read Middle School

- McCullough Middle School

- Springer Junior High School

- Alfred G Waters Middle School

- The Bayard School

High Schools (20)

- Newark Charter School*

- Newark High School

- Christiana High School

- Glasgow High School

- Paul M. Hodgson Vocational High School

- Thomas McKean High School

- Saint Mark's High School

- The John Dickinson School

- A.I. du Pont High School

- Sussex Academy of Arts and Sciences

- Conrad Schools of Science

- Caesar Rodney High School

- Mount Pleasant High School

- Concord High School

- Middletown High School 


\section{- Appoquinimink High School}

- Brandywine High School

- Dover High School

- Smyrna High School

- Delmar High School

Copyright (c) 2021 Delaware Academy of Medicine / Delaware Public Health Association.

This is an Open Access article distributed under the terms of the Creative Commons Attribution Non-Commercial License (https://creativecommons.org/licenses/by-nc-nd/4.0/) which permits unrestricted non-commercial use, distribution, and reproduction in any medium, provided the original work is properly cited. 